\title{
DEVELOPMENT OF A WIRELESS ACTIVE SYSTEM FOR TPS STRUCTURAL HEALTH MONITORING
}

\author{
Victor Giurgiutiu $^{1}$, Buli $\mathrm{Xu}^{1}$, Jaycee Chung ${ }^{2}$ and JonPaul Laskis ${ }^{1}$ \\ ${ }^{1 .}$ Mechanical Department, University of South Carolina, Columbia, SC 29208, USA \\ ${ }^{2}$ Global Contour Ltd., 1145 Ridge Road West Rockwall, TX 75087-3111, USA
}

\begin{abstract}
This paper presents how active SHM principles could be applied for the detection and monitoring of critical TPS damage. Several essential aspects are being studied: (a) development of high temperature piezoelectric wafer active sensor (HT-PWAS) that can survive the harsh environment to which the TPS are exposed; (b) development of active SHM (pitch-catch, pulse-echo, phased-array, electromechanical impedance) that can be applied to TPS; (c) development of self-powering low-power consumption electronics with wireless transceiving capabilities.
\end{abstract}

Keywords: Structural health monitoring, piezoelectric wafer active sensors, TPS, harsh environment PACS: $43.40 .+\mathrm{s}$

\section{INTRODUCTION}

Structural health monitoring (SHM) using in-situ active sensors has shown considerable promise in recent years. Small and lightweight piezoelectric wafer active sensors (PWAS), which are permanently attached to the structure, are used to transmit and receive interrogative Lamb waves that are able to detect the presence of cracks, disbonds, corrosion, and other structural defects. Successful demonstrations of active SHM technologies have been achieved for civil and military aircraft components and substructures. The two major new aircraft programs (e.g., Boeing 787 and Airbus A380) both envision the installation of SHM equipment throughout the critical structural areas. However, the use of active SHM in harsh elevated temperature environments has not been yet explored. The main reason for this situation is that the commonly used piezoelectric material, $\mathrm{PZT}$, or $\mathrm{PbZrTiO}_{3}$ cannot be used above $260^{\circ} \mathrm{C}\left(500^{\circ} \mathrm{F}\right)$.

Nevertheless, USAF has a considerable number of critical applications, which are subjected to extreme environments and elevated temperatures, and are in need of structural health monitoring technologies [1][2]. One example is the Space Operations Vehicle, which is going to be subject to extreme environmental conditions. Affordability requires reduction in launch costs. Reducing the turn-around time is the key to reducing costs. The rapid assessment of vehicle health is essential to reducing the turn-around time. Of considerable interest is the structural health of the thermal protection system (TPS). 


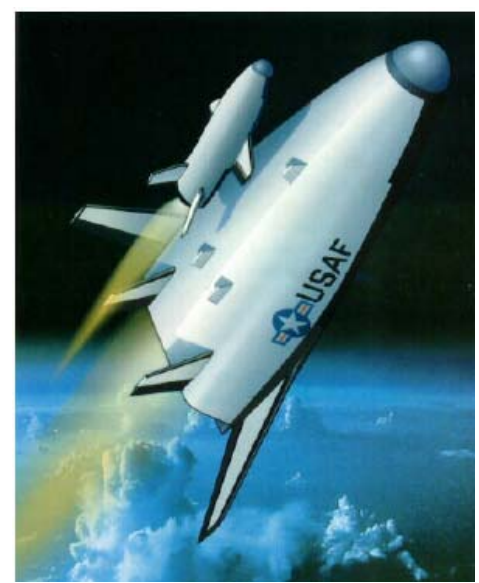

(a)

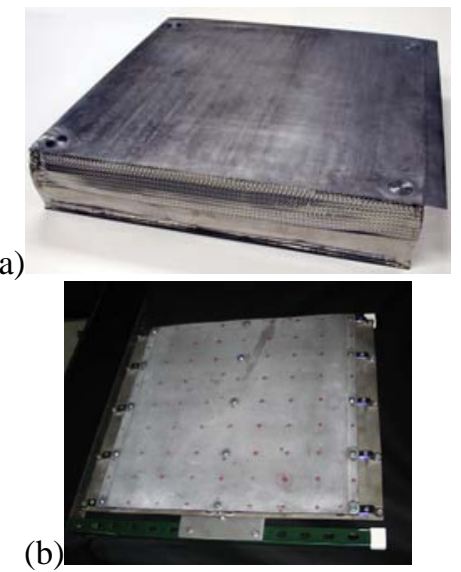

Figure 1. Space Operations Vehicle TPS variants: (a) metallic honeycomb; (b) carbon-carbon composites

The TPS is built to accommodate aerodynamic pressures, as well as thermal conditions found in the cold of space and throughout the heat of reentry (Figure 1). Several TPS tile variants are being considered. One variant consists of an outer surface of foil-gage Inconel 617 metallic honeycomb sandwich panel (Figure 1a). This outer panel is structurally connected to an inner box beam by a thin Inconel 718 metal support bracket at each corner of the panel. Another variant considers carbon-carbon composites fastened to ribbed titanium backing structure (Figure 1b). The active SHM principles could be applied for detection and monitoring of critical TPS damage if the active sensors could sustain the harsh temperature environment.

This paper addresses the development of active SHM technology for in-situ interrogation of damage state in structural materials subjected to harsh/extreme environments. Several essential aspects are being studied: (a) development of high temperature piezoelectric wafer active sensor (HT-PWAS) that can function in the harsh environment to which the TPS are exposed; (b) development of active SHM (pitch-catch, pulse-echo, phased-array, electromechanical impedance) that can be applied to the specific constructions; (c) development of self-powering low-power consumption electronics with wireless capability for implementing the active SHM principles, and transmit the diagnostic results.

\section{STATE OF THE ART}

Ref. [3] shows that the active SHM technology has found many applications in airframes, land vehicles, ships, and civil engineering structures. A comprehensive survey of the sensors technologies for evaluating the damage states in materials and structures for vehicle health monitoring can be found in ref. [4]. A detail description of the University of South Carolina multi-method approach to structural health monitoring using piezoelectric wafer active sensors (PWAS) is given in ref. [5]. It shows that PWAS can be used as both active and passive probes that can address four SHM needs:

1. Active sensing of far-field damage using pulse-echo, pitch-catch, and phased-array methods

2. Active sensing of near-field damage using high-frequency impedance method

3. Passive sensing of crack initiation and growth through acoustic emission

4. Passive sensing of damage-generating events through detection of low-velocity impacts

For harsh/extreme environment applications, only a few tentative trials have so far been reported. PWAS in conjunction with the electromechanical (E/M) impedance method 
were tried for monitoring structural damage in turbo engine blades [6]. However, the experiments were impended by the low temperature tolerance of the PZT material and the need for transferring data from a rotating frame. Yang and Chang et al. [7] considered the use of built-in piezoelectrics for indirectly detecting impact and damage in TPS tile by monitoring the cooler attachments points with ingeniously conceived piezo washers. Rosenstengel and Olson et al [8] also studied the feasibility of using active SHM on TPS tiles to indirectly detect TPS fasten failure by placing piezoelectric transducers not on the TPS tile but on the cooler support structure. It is apparent that the temperature limitation of conventional piezoelectric materials presents a major obstacle in the application of active SHM methods to harsh/extreme environment operating structures.

\section{DEVELOPEMNT OF HIGH-TEMPERATURE PIEZOELECTRIC WAFER ACTIVE SENSORS (HT-PWAS)}

The preparation of PWAS for SHM in room temperature is already well established. Commercial ferroelectric PWAS (e.g., APC 850 with silver electrodes, Curie temperature at $360^{\circ} \mathrm{C}$ ) is usually bonded to the structure under monitoring with regular adhesive (e.g., M-bond 200, Vishay). To instrument the sensor, a wire is always soldered to one of the electrodes of the sensors. Nevertheless, for SHM in harsh environment which contains oxidative/corrosive conditions with high $\mathrm{G}$ loads and in elevated temperatures that may exceed $700^{\circ} \mathrm{C}\left(1300^{\circ} \mathrm{F}\right)$, piezoelectric materials of the sensor, electrodes of the sensors, selection of wiring and adhesive must be reconsidered.

\section{$\underline{\text { Identification of High-Temperature Piezoelectric Materials }}$}

Recent developments in piezoelectric materials have brought forwards classes of materials that preserve their piezoelectric properties at elevated temperatures. There are several requirements that must be rigorously addressed when considering piezoelectric materials for high temperature applications [9][10]. The Curie transition temperature must be well above the operating temperature; otherwise the piezoelectric material may depolarize under combined temperature and pressure conditions. The thermal energy causes displacement of domain walls, leading to the large power dissipation and hysteretic behavior, especially when temperature is close to the Curie transition temperature. The temperature variation may produce pyroelectric charges, which may interfere with the piezoelectric effect. In addition, many ferroelectrics become conductive at high temperatures, leading to the charge drifts and partial loss of signal. The conductivity problem is aggravated during operation in atmosphere with low oxygen content, in which many oxygen-containing ferroelectrics may rapidly loose oxygen and become semi conductive.

Strong candidates for the high temperature piezoelectric applications are the nonferroelectric piezoelectric Aluminum Nitride $(\mathrm{AlN})$ and Gallium Orthophosphate $\left(\mathrm{GaPO}_{4}\right)$.

Aluminum nitride (AlN) has a wurtzite structure, and is pyroelectric. It does not exhibit phase transitions on heating from room temperature, and melts at above $2000^{\circ} \mathrm{C}$ in a nitrogen atmosphere. This piezoelectric material retains its properties above $1000^{\circ} \mathrm{C}$. It has a high electrical resistivity even at elevated temperatures [9]. Because it does not contain oxygen in its composition, AlN can safely operate at low partial pressures of oxygen, such as in a neutral $\left(\mathrm{N}_{2}\right)$ atmosphere at high temperatures, under conditions where most other piezoelectric materials (especially ferroelectrics) will loose its functional properties and become electrically conductive. Under funding from AFRL NDE Branch [11], University of Dayton Research Institute (UDRI) has demonstrated a high temperature AlN ultrasonic transducer that can operate at over $900^{\circ} \mathrm{C}\left(1650^{\circ} \mathrm{F}\right)$ and $140 \mathrm{MPa}(\sim 20 \mathrm{ksi})$. UDRI also patented the used of AIN in ultrasonic transducers (US Patent \#5,886,456). 
Figure 2. ALN high-temperature ultrasonic sensor

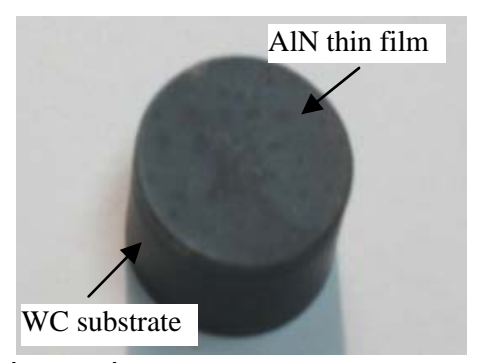

(a)
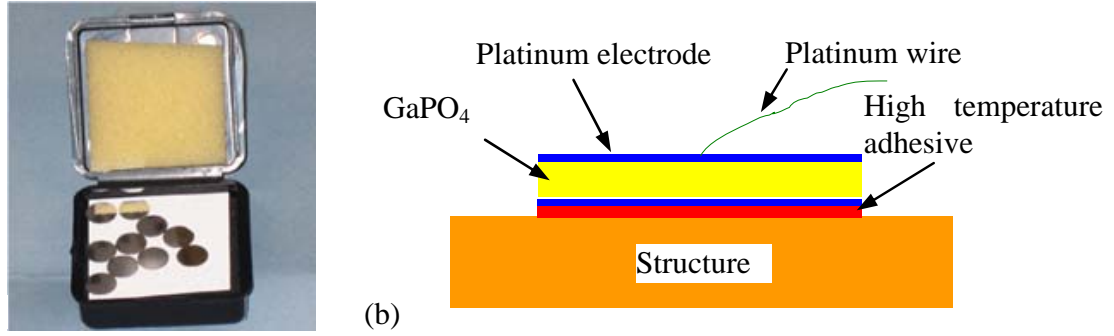

Figure 3. GaPO4 sensors: (a) sensor picture; (b) sensor bonded on structure

In another application [12], AlN film ultrasonic sensor were demonstrated capable of emitting and receiving ultrasonic energy at temperature exceeding $900^{\circ} \mathrm{C}\left(1650^{\circ} \mathrm{F}\right)$ and pressures above $150 \mathrm{MPa}(\sim 22 \mathrm{ksi})$. Furthermore, an AlN thin film pressure sensor was developed to monitor pressure fluctuations in rotating machinery on both the blade surfaces and the casing at temperature above $500^{\circ} \mathrm{C}\left(\sim 930^{\circ} \mathrm{F}\right)$ and centrifugal acceleration up to $300,000 \mathrm{~g}$ [13]. The sensor was less than $20 \mu \mathrm{m}$ thick and consisted of a triple-layer structure of $\mathrm{Pt} / \mathrm{AlN} / \mathrm{Pt}$ representing the measurement electrode, the piezoelectric element, and the shielding electrode that were deposited by cathode sputtering. The sensor electrical properties were evaluated up to $900^{\circ} \mathrm{C}$ in the range $100 \mathrm{~Hz}$ to $1 \mathrm{MHz}$. Figure 2 shows a sample of AIN film obtained from UDRI. The AIN film was deposited on tungsten carbide substrate. The conductive substrate acts as one of the electrodes. Another electrode will be prepared by pressing the sensor against a metal plate or by applying a conductive coating.

Gallium orthophosphate $\left(\mathrm{GaPO}_{4}\right)$ is considered the "high temperature brother of quartz" [14]. It shows remarkable thermal stability up to temperatures above $970^{\circ} \mathrm{C}$. Furthermore, it displays no pyroelectric effect and no out-gassing. It has a high electric resistivity that guarantees high-precision piezoelectric measurements. The first industrial application of $\mathrm{GaPO}_{4}$ single crystals was in uncooled miniaturized pressure transducers for internal combustion engines using the direct piezoelectric effect. These sensors are produced since 1994, and are now well established on market [15]. Figure 3 shows the Gallium orthophosphate $\left(\mathrm{GaPO}_{4}\right)$ sensors obtained from Piezocryst Inc., Austria. The sensors are $\mathrm{x}$-cut $\mathrm{GaPO}_{4}$ single crystal discs with a triple-layer structure (measurement electrode, $\mathrm{GaPO}_{4}$ piezoelectric thin film and measurement electrode), $7 \mathrm{~mm}$ diameter and $0.2 \mathrm{~mm}$ thickness. The electrodes are sputtered Pt-layer with a thickness of $100 \mathrm{~nm}$.

\section{Identification of Electrodes and Wiring of High-Temperature Sensors}

High-temperature electrode materials can be divided into three groups [16]: (a) metals (e.g., Ti, W, Pt, Rh, Ir); (b) alloys (e.g., NiCr, CuAl); and (c) metal-nonmetal compounds (e.g., ceramic electrodes, TiN, CoSi2, WC).

Metals with a high melting point and noble character appear most suited for high temperature applications, e.g., platinum (Pt), rhodium (Rh) or iridium (Ir). Because of the availability and a greater experience in processing and deposition, Pt (with melting point around $1800^{\circ} \mathrm{C}$ ) is the high temperature electrode material of choice. 
Table 1. List of high-temperature bonding compounds

\begin{tabular}{cccc} 
Item & Manufacturer & Model & Temperature \\
M-Bond & Vishay & M-Bond 600 & $260^{\circ} \mathrm{C}\left(500^{\circ} \mathrm{F}\right)$ \\
Strain Gain Cement & Vishay & GC cement & $1093^{\circ} \mathrm{C}\left(2000^{\circ} \mathrm{F}\right)$ \\
Strain Gain Cement & Vishay & H cement & $1093^{\circ} \mathrm{C}\left(2000^{\circ} \mathrm{F}\right)$ \\
Silver epoxy & Aremco & Aremco-Bond ${ }^{\mathrm{TM}} 597$ & $870^{\circ} \mathrm{C}\left(1600^{\circ} \mathrm{F}\right)$ \\
Ceramic adhesive & Aremco & Aremco-Bond & \\
\hline
\end{tabular}

Considering the thermal expansion at high temperature, $\mathrm{Pt}$ wire welded to the sensor $\mathrm{Pt}$ electrode will serve as the wiring for the instrumentation of the sensor.

\section{Identification of High-Temperature Adhesives}

Due to the high temperatures involved in this application, extra care needs to be taken for the bonding of sensors. Other investigators [17] have found that the epoxy adhesive, such as M-bond, supplied with commercial PZT patches softens at higher temperatures. We found more commercially available bonding compounds (e.g., GC cement, $\mathrm{H}$ cement, and ceramic adhesives) that may meet the high temperature requirement of harsh environment. Table 1 lists a number of adhesives, their manufactures and maximum working temperatures.

The review of the state of the art presented in previous section indicates that a number of high-temperature piezoelectric materials (Gallium orthophosphate, aluminum nitrate, and possibly others) are commercially available. Also available are hightemperature bonding compounds (Table 1) and high-temperature wiring options (Pt, Rh, Ir). We will utilize commercially available high-temperature piezoelectric materials, bonding compounds, and wiring to develop high-temperature piezoelectric wafer active sensors (HT-PWAS) systems suitable for in-situ damage detection under harsh/extreme environments. The developed system will be subjected to coupon qualification tests on metallic specimens in a range of temperatures up to $900^{\circ} \mathrm{C}\left(\sim 1650^{\circ} \mathrm{F}\right)$ and under various static and fatigue loading conditions. In performing this work, we will build on the environmental and load-testing experience with conventional PWAS accrued during our previous work for AFRL NDE branch [18].

\section{HT-PWAS DAMAGE DETECTION STRATEGIES FOR TPS TILES}

An ideal application of our HT-PWAS could be SHM of the TPS tiles of the USAF's Space Operations Vehicle. In our previous work for AFRL NDE branch [18], we reported a phased-array damage detection technology that allowed the imaging of large panel areas from a single location using in-situ generation and reception of guided Lamb waves with PWAS phased arrays. This approach, called embedded ultrasonics structural radar (EUSR) is different from the conventional phased arrays because:

1. It uses embedded PWAS transducers which are small, inexpensive, and minimally invasive.

2. It works in virtual time, not in real time, thus requiring a bare minimum of equipment.

Also, in our previous work [18], we have shown that the PWAS EUSR technology can detect small cracks, and even pin holes in large panels from a single location without being affected by panel curvature or environmental vibrations. Figure 4 shows the pictures of EUSR technology detecting a simulated crack in a large aluminum panel.

We will attempt to utilize the EUSR phased-array approach with the HT-PWAS developed during this project, and will verify its functional validity on refractory alloys and carbon-carbon composites of envisioned applications to TPS. Since the HT-PWAS can withstand high temperatures, we envision installing the transducers directly on the TPS tiles, which has not been attempted by others. Two placement options will be considered: 

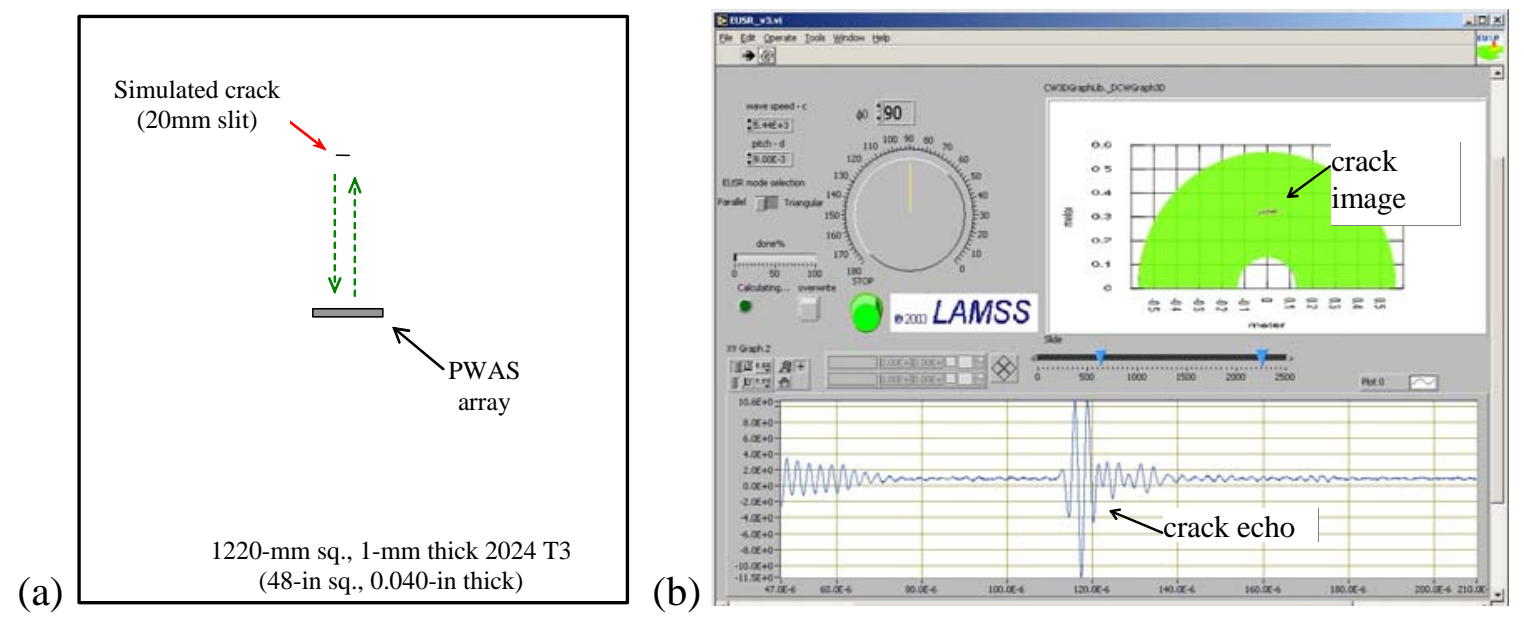

Figure 4. Phased-array crack detection in a large panel: (a) location of PWAS array and simulated crack; (b) A-scan indicating crack echo and imaging of the half-plate with the EUSR algorithm.

1. HT-PWAS placed on the outer surface of the TPS tile. This will permit direct measurements of the material damage that is expected to initiate from the outer surface, which is subjected to the most severe environmental exposure.

2. HT-PWAS placed on the inner surface of the TPS tile. This option will subject the HT-PWAS to less severe temperature range, but may require more elaborate damage detection methods.

We will perform coupon testing at various temperatures in the TPS operational temperature ranges. Thus, we will determine if the HT-PWAS can withstand the temperatures anticipated for the outer and inner TPS tiles. Besides the EUSR technology, we will utilize the same HT-PWAS installation to perform damage detection tests with the pitch-catch and E/M impedance technique. In addition, continuous impact detection monitoring will be attempted with the same HT-PWAS installation by supplementing the electronics with an event watchdog module.

\section{SELF-POWERING WIRELESS ACTIVE STRUCTURAL HEALTH MONITORING SENSOR (SP-WASHMS) SYSTEM}

To implement the SHM principles and transmit the diagnostic results, a selfpowering wireless active structural health monitoring sensor (Sp-WASHMS) system/mote is being developed using HT-PWAS as its primary structural health diagnostic means by Global Contour Ltd. A generic system level concept of this wireless sensor platform is shown in Figure 5. It consists of sensor interface block, processing block, transceiver block and power supply (battery charged by energy scavenger). The Sp-WASHMS is a multifunctional sensor node, which performs such functions as power harvesting, structural health diagnosis (SHM), local signal processing and wireless transceiving. The wasted vibration energy and thermal energy-based power harvesting circuitry is being developed to power the sensor system. The wireless transceiver module is a critical component in the sensor motes. There are many different wireless transceiver modules available on market, such as Xbee, XBee-pro, AC4424, AC4790, ConnexLink CL4424, Wi232DTS, and PromiSD101. Ultra Wide Band (UWB) wireless transceiver technology is under development by Global Contour Ltd. The UWB will offer greater throughput scalability, lower power consumption, high data rates, reduced multi-path fading, self-localization, etc. In addition, a sensor network based on the proposed wireless sensor platform can be formed to facilitate SHM of structure with large number of sensors. 


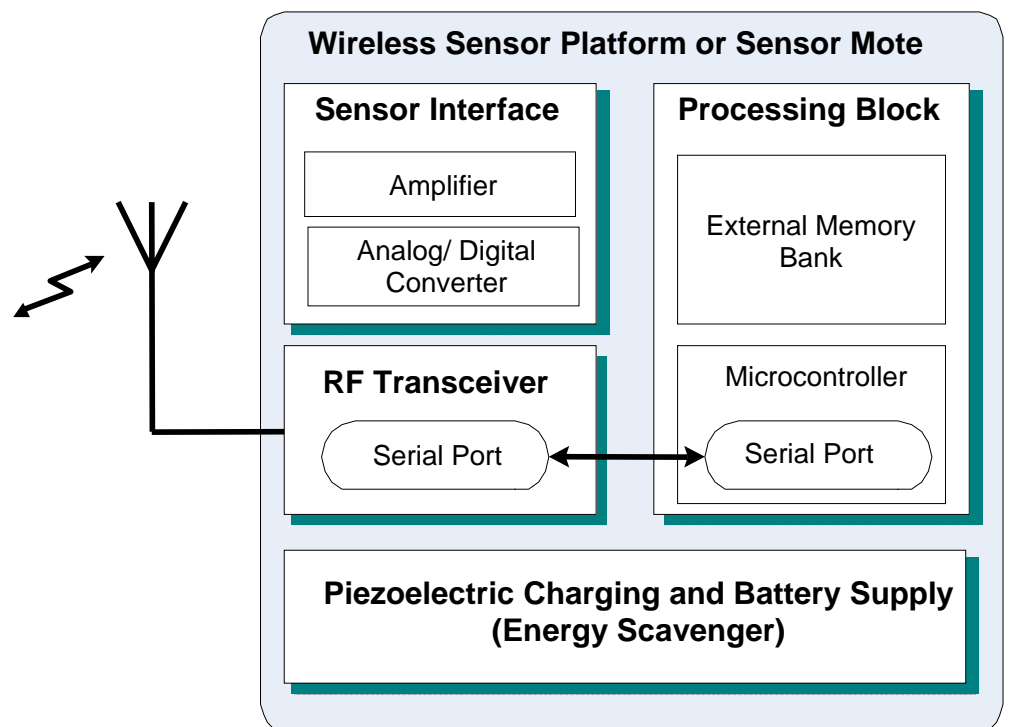

Figure 5. Architecture of self-powering wireless active structural health monitoring sensor (SpWASHMS) system/mote.

The sensor network can be adapted to point-to-point or point-to multipoint, client-server or peer-to-peer architecture.

\section{DISCUSSIONS AND CONCLUSIONS}

The paper presented the development of HT-PWAS and proposed the SHM strategies for TPS SHM with HT-PWAS in harsh/high temperature environment. In addition, to facilitate the implementation of SHM principles and transmission of diagnosis results, a conceptual Self-powering Wireless Active Structural Health Monitoring Sensor (Sp-WASHMS) system is proposed. We envision that the HT-PWAS technology will open a variety of implementation options for USAF's Space Operations Vehicles thermal protection systems. After being proven successful, this technology might be also applicable to the USAF aircraft jet engine and other reusable launch vehicles as well as NASA's present Space-Shuttle and future Crew Exploration Vehicle (CEV). Our HT-PWAS possesses multiple diagnostic capabilities, and those are phased-array, pitch-catch, E/M impedance, and impact detection.

\section{ACKNOWLEDGEMENTS}

The presented research was performed under AF05-136 SBIR phase I (FA8650-05M-5209). Dr. Kumar Jata of the USAF and Dr. Todd Steyer of Boeing Company are sincerely acknowledged for their support.

\section{REFERENCES}

1. AFRL Health Management Technical Review, 3-4 June 2003, Dayton, OH

2. AFRL Integrated Systems Health Management Conference, 17-19 August 2004, Dayton, $\mathrm{OH}$

3. Structural Health Monitoring - International Workshop, 1997, 1999, 2001, 2003, Stanford University, Fu-Kuo Chang (Editor)

4. Jata, K.; Blackshire, J.; Adams, D. "A Survey of Sensor Technologies for Evaluating Damage States in Materials and Structures for Vehicle Health Monitoring”, Aeromat 2004, June 7-10, 2004, Seatlle, WA

5. Giurgiutiu, V. ; Lyshevski, S. E., Micromechantronics, CRC Press, 2004 (Chapter 11: Piezoelectric wafer active sensors) 
6. Winston, H. A.; Sun, F.; Annigeri, B. S. "Structural Health Monitoring with Piezoelectric Active Sensors”, ASME Turbo Expo 2000, ASME paper \#2000-GT-0051, Munich, Germany (www.asme.org)

7. Yang, J.; Chang, F. K.; Derriso, M. M., "Design of a Hierarchical Health Monitoring System for Detection of Multilevel Damage in Bolted Thermal Protection Panels: A Preliminary Study”, Structural Health Monitoring, Vol 2(2), P115-122, 2003

8. Rosenstengel, J.; Miller, I.; DeSimio, M.; Derriso, M.; Brown, K.; Braisted, W.; Olson, S.; "Detection of Fastener Failure In A Thermal Protection System Panel", 2004 IEEE Aerospace Conference Proceedings, Vol 4, pp. 2464 - 2473, 6-13 Mar, 2004

9. Damjanovic, D. (1998) "Materials for High Temperature Piezoelectric Transducer”, Current Opinion in Solid State \& Materials Science, Vol. 3, pp. 469-473, 1998

10. Tuner, R. C.; Fuierie, P. A.; Newnham, R. E.; Shrout, T. R. (1994), “ Materials for High Temperature Acoustic and Vibration Sensors: A Review”, Applied Acoustics, Volume 41, 1994, pp. 299-324

11. Sebastian, J. (2004), "Elevated Temperature Sensors for On-line Critical Equipment Health Monitoring”, University of Dayton Research Institute, Department of Energy Review Meeting, Online presentation, June, 9, 2004.(http://www.netl.doe.gov/publications/proceedings/04/UCRHBCU/presentations/Sebastian_P.pdf)

12. Stubbs, D. A.; Dutton R. E. (1996), “ An Ultrasonic Sensor for High-Temperature Materials Processing”, JOM-a publication of The Minerals, Metals \& Materials Society, Volume 48, Number 9--September 1996, pp. 29-31

13. Kayser, P.; Thobois, P.; Cageant, C. (2000), “Pt/AlN/Pt Piezoelectric Transducer for Unsteady Pressure Sensor in Rotating Machines”, Physics, Instrumentation and Sensing Department, http://www.onera.fr/dmph-en/capt_cou_min/

14. http://www.gapo4.com

15. Krispel, F. et al; (2003), "Properties and applications of singly rotated $\mathrm{GaPO}_{4}$ resonators”, Frequency Control Symposium and PDA Exhibition Jointly with the 17th European Frequency and Time Forum ,Proceedings of the 2003 IEEE International , 48 May 2003, pp. $668-673$

16. Hornstainer, J., et al (1998) "Surface Acoustic Wave Sensor for High Temperature Applications”, Frequency Control Symposium, 1998, Proceedings of the 1998 IEEE International , 27-29 May 1998 Pages:615-620

17. Schulz, M. J.; Sundaresan, M. J.; McMichael, J.; Clayton, D.; Sadler, R.; Nagel, B. (2003), “ Piezoelectric Materials at Elevated Temperature”, Journal of Intelligent Material Systems and Structures, Vol. 14, Nov. , 2003

18. Giurgiutiu, V. “Structural Monitoring with Piezoelectric Wafer Active Sensors”, Final Report \#USC-ME-LAMSS-2003-101, presented to AFRL NDE Branch, contract TOPS-DO-033-USC, July 2004 